NICOLAS NAJJAR

Curtin University of Technology

nicolas.najjar@postgrad.curtin.edu.au

ORCID: 0000-0001-7787-0395

\title{
STUDIES ON FACTORS INFLUENCING SYNTACTIC TRANSFER IN L3 ACQUISITION
}

Keywords: Third Language Acquisition (TLA), Third Language Acquired (L3), Second Language Acquired (L2), First Language Acquired (L1)

\begin{abstract}
This paper examines the factors influencing syntactical transfer in TLA. There are several factors that influence syntactic transfer in TLA: linguistic (such as typology); individual (such as learners' "attention control" and age); psycho-linguistic (such as psychotypology and the learners' awareness of cognates); and other factors (such as L2 type and amount of instruction). In summary, it was found that negative syntactic transfer from both $\mathrm{L} 1$ and L2 to L3 occurs when (a) languages are typologically dissimilar (b) learners' "attention control ability" is low, and (c) L2 level of proficiency and exposure is advanced and $\mathrm{L}_{3}$ level of proficiency is low. In contrast, positive syntactic transfer from L1 and $\mathrm{L}_{2}$ to $\mathrm{L}_{3}$ occurs when (a) languages are typologically similar, (b) students perceive these languages as similar, and (c) L1 and L2 level of proficiency is high and $\mathrm{L}_{3}$ level of proficiency is low. Additionally, the learners' age was found to potentially influence the language (L1 or L2) from which the transfer occurs into $\mathrm{L}_{3}$ : $\mathrm{L}_{3}$ adult learners may count more on their $\mathrm{L}_{2}$ as a source of positive syntactic transfer into $\mathrm{L}_{3}$ whereas children may count more on their $\mathrm{L}_{1}$ as a source of positive syntactic transfer into L3. Finally, it was found that when L1, $\mathrm{L}_{2}$, and $\mathrm{L}_{3}$ are equally proximate, it is the $\mathrm{L}_{2}$ that has the primary influence on positive and negative syntactic transfer in TLA.
\end{abstract}

\section{Introduction}

Grammatical transfer in TLA is the transfer of grammatical features across three learned or acquired languages. Grammatical transfers mainly include - but are not limited to - syntactic transfers. Syntax is the set of rules that determine and govern 
the structure of sentences in a given language; this mainly concerns word order. Ellis et al. (2009) identified the factors that influence grammatical transfer from L1 to L2. This paper applies Ellis et al.'s (2009) framework to show the factors that influence grammatical transfer in TLA in cases of transfer from L1 and L2 into L3. This paper argues that syntactic transfer in TLA is influenced by the following five factors: linguistic, psycho-linguistic, contextual, learner's proficiency of their three languages, developmental and individual differences. Some of the studies investigated in this paper demonstrate the transfer effect of both $\mathrm{L}_{1}$ and $\mathrm{L}_{2}$ into $\mathrm{L}_{3}$ (Rothman 2010; García Mayo, Slabakova 2015). Other studies sought to investigate the relative transfer effect of L1 and L2 under different conditions (Flynn et al. 2004; Bardel, Falk 2007; Rothman, Cabrelli 2010; Falk, Bardel 2011; Falk et al. 2015; Hermas 2015; Pfenninger, Singleton 2016; Sanchez, Bardel 2016; Berns et al. 2018). This paper will focus entirely on "Forward Syntactic Transfer". This phenomenon occurs when syntactic features from previously learned languages are transferred into a newly learned language. A discussion on "Backward Lexical Transfer" is not included in this paper. More emphasis is placed on "Foreword Syntactic Transfer" due to its potential to assist in learning a new language by making use of a learner's existing $\mathrm{L}_{1}$ and L2 syntax to assist with the development of their L3 syntax. "Forward Syntactic Transfer" is from (L1) or (L2) into participants $\left(\mathrm{L}_{3}\right)$ syntactic production. This paper explores studies in which there are either differences or similarities between participants' $\mathrm{L}_{1}$ and $\mathrm{L}_{2}$ syntax and their $\mathrm{L}_{3}$ syntax. The differences that this paper identifies create a potential for negative syntactic transfer. However, as is now well documented in the transfer literature, similarities in syntactic rules across related languages do not always lead to positive syntactic transfer nor do dissimilarities in syntax across related languages always lead to negative syntactic transfer. Positive and negative syntactic transfer can be a product of learning instruction. Therefore, this paper will critique the applicability of the methodology utilized by the studies investigating syntactic transfer in TLA. In conclusion, this paper will suggest a more valid approach to investigate syntactic transfer in TLA, and reiterate the impact of the aforementioned factors on syntactic transfer in TLA.

\section{Typological dissimilarity}

Syntactic transfer from $\mathrm{L}_{1}$ and $\mathrm{L}_{2}$ into $\mathrm{L}_{3}$ has been found to be influenced by the typological dissimilarity between these languages. This section investigates the influence of this factor.

García Mayo and Slabakova (2015) investigated the influence of typological dissimilarity of $\mathrm{L}_{1}$ and $\mathrm{L}_{2}$ with $\mathrm{L}_{3}$ in the syntactic production of $\mathrm{L}_{3}$. In this study three groups were recruited.

- Group A ( $\mathrm{n}=23$ ) comprised L1 Basque, L2 Spanish and L3 English.

- Group B ( $\mathrm{n}=25)$ included L1 Spanish, L2 Basque and L3 English.

- Group C ( $\mathrm{n}=47)$ consisted of L1 Spanish and L2 English learners. 
The critical issue affecting transfer from $\mathrm{L}_{1}$ or $\mathrm{L}_{2}$ into $\mathrm{L}_{3}$ is the difference between the manner in which Spanish and Basque treats the grammatical feature of "dropping the clitic" in responses to questions with "indirect unspecific" objects. In the Basque language, when a question contains an "indirect unspecific" object answers to this question are considered grammatically correct whether or not they contain a clitic. By contrast, English grammar does not follow this rule and answers for questions containing "indirect unspecific" object must always contain a clitic. Consequently negative syntactic transfer by English learners with a previous knowledge of Basque can occur (García Mayo, Slabakova 2015). The example below illustrates this point.

In questions 1 and 2 below, the object (coffee) is indirect and unspecific. Only answer (a) is grammatically correct in English. By contrast, both the answer with the "clitic" (c) and the one with the "dropped clitic" (d) are grammatically correct in Basque.

1. Question in English: "Did they bring coffee for dinner?" (coffee: indirect unspecific object)

- Answer (a) English language: "Yes, they bought some (some: clitic)." Grammaticality of the answer in English: Grammatically correct

- Answer (b) English language: "Yes, they bought $\varnothing$ (dropped clitic)." Grammaticality of the answer in English: Grammatically incorrect

2. Question in Basque: "Kafea ekarri zuten afaltzeko?"

English word for word translation: "Did they bring coffee for dinner?"

- Answer (c) Basque language: "Bai, batzuk ekarri dituzte.) (Batzuk: clitic).”

English word for word translation: "Yes, they bought some."

Grammaticality of the answer in Basque: Grammatically correct

- Answer (d) Basque language: "Bai Ø ekarri zuten) (dropped clitic)."

English word for word translation: "Yes, they bought."

Grammaticality of the answer in Basque: Grammatically correct

In Spanish it is only considered grammatically correct to drop the clitic if a question contains an "indirect unspecific" object. As English grammar does not allow this Spanish grammatical rule, English learners with previous knowledge of Spanish can transfer this syntactic feature into English. Consequently negative syntactic transfer by English learners with a previous knowledge of Spanish can occur. The examples below illustrates this point. In questions 3 and 4 below, the object "coffee" is indirect and unspecific. Only answer (a) which includes a "clitic" is grammatically correct in English. By contrast, both the answer with the "clitic" (c) and the one with the "dropped clitic" (d) are grammatically correct in Spanish.

3. Question in English: "Did they buy coffee for dinner?" (coffee: indirect unspecific object)

- Answer (a) English language: "Yes, they bought some (some: clitic)." Grammaticality of the answer in English: Grammatically correct

- Answer (b) English language: "Yes, they bought $\varnothing$ (dropped clitic)." Grammaticality of the answer in English: Grammatically incorrect 
4. Question in Spanish: “¿Compraron café para la cena?”

English word for word translation: "Did they buy coffee for dinner?"

- Answer (c) Spanish language: "Si ellos compraron algunos (Algumos: clitic)." English word for word translation: "Yes, they bought some."

Grammaticality of the answer in Spanish: Grammatically correct

- Answer (d) Spanish language: "Si ellos compraron $\varnothing$ (dropped clitic)."

English word for word translation: "Yes, they bought."

Grammaticality of the answer in Spanish: Grammatically correct

Participants were presented with twelve questions in English of which six questions contained "indirect unspecific" objects. Two answers are supplied with each question, only one of which is correct (the sentence incorporating the clitic). Participants were asked to choose the correct answer. Participants in all three groups had an advanced level of $\mathrm{L}_{2}$ proficiency in either Spanish or Basque and an intermediate level of $\mathrm{L}_{3}$ English. Participants were exposed to Spanish and English through the school system. Participants were exposed to English at a mean age of 8.18 (SD 2.98, range $4-18)$.

The rate of acceptance of dropping the "clitic" for questions with "indirect unspecific" objects among the bilingual participants in Group $\mathrm{C}(\mathrm{M}=52.3 \%)$ was inferior to that of the trilingual participants in Group A ( $M=57.3 \%)$ and Group B $(M=58 \%)$. Results showed a higher rate of negative syntactic transfer in group A and B than in Group C. The researchers argued the results provided evidence of cumulative negative syntactic transfer among participants with two non-English languages. One of the limitations of this study resides in its method of evaluating $\mathrm{L}_{3}$ level of proficiency. This is because the number of years of exposure to a foreign language does not fully determine the level of proficiency of a given language.

In Summary this study suggested that in TLA negative syntactic transfer from a previously learned language into L 3 occurs when these languages are typologically dissimilar.

Rothman (2010) investigated the impact of typological similarity and dissimilarity across related languages on syntactic transfer in TLA. In his study participants formed two groups, both of whom had advanced L2 level of proficiency. Group A $(n=15)$ had L1 Spanish, L2 English and L3 Brazilian-Portuguese. Group B $(n=16)$ had L1 English L2 Spanish and L3 Brazilian-Portuguese. Prior to commencement of the study, all participants were enrolled for four weeks in a Brazilian-Portuguese language course. Learners were tested after approximately fifty-five to seventy-five hours of classroom instructions in $\mathrm{L}_{3}$ Brazilian Portuguese. Prior to the commencement of the study all students lived with Brazilian families. Participants had approximately two hundred hours of exposure to authentic Brazilian Portuguese language. The researcher postulated that participants' $\mathrm{L}_{3}$ level of proficiency was elementary due to the limited amount of $\mathrm{L}_{3}$ instruction and exposure.

The critical issue affecting transfer from $\mathrm{L}_{1}$ or $\mathrm{L}_{2}$ into $\mathrm{L}_{3}$ is the difference between the way in which Spanish and English treat the "verb-second" (V2) word order in cases where the verbs belong to the following three categories: 1) transitive 
verbs, 2) intransitive verbs, 3) accusative verbs. The following paragraphs will illustrate the case.

English and Brazilian Portuguese both follow the V2 rule in the construction of a declarative sentence with transitive verb. Transitive verbs are verbs that allow one or more objects as in the sentence "I admire your courage and honesty." In contrast, in Spanish declarative sentences with transitive verbs are considered grammatically correct whether or not its word order construction follows the (V2) rule. This constituted a potential case of negative syntactic transfer from Spanish to Brazilian Portuguese. The examples below illustrate the case.

Example of an English sentence with a "Transitive Verb":

"I (subject) admire (transitive verb) your knowledge (object)."

a) First correct translation in Spanish:

"Yo (I: subject), admiro (admire: transitive verb) tu conocimiento (your knowledge: object)."

b) Second correct translation in Spanish:

"Tu conocimiento (your knowledge: Object) yo (I: subject) Admiro (Admire: transitive verb)."

c) Correct translation in Brazilian-Portuguese:

"Eu (Subject: I) admiro (transitive verb: admire) seu conhecimento (object: your knowledge)."

d) Incorrect translation in Brazilian-Portuguese:

"Seu conhecimento (object: your knowledge) eu (subject: I) admiro (admire: transitive verb)."

English and Brazilian Portuguese both follow the V2 rule in the construction of a declarative sentence with an intransitive verb. Intransitive verbs are verbs that do not permit a direct object, as in the sentence "The kid smiles." By contrast, in Spanish declarative sentences with intransitive verbs are considered grammatically correct whether or not its word order construction follows the (V2) rule. This constituted a potential case of negative syntactic transfer from Spanish into Brazilian Portuguese. The examples below illustrate the case.

Example of a correctly structured English sentence with an "Intransitive Verb": "The kid (Subject) smiles (Verb)."

a) The first correct translation in Spanish:

"El niño (Kid: Subject) sonríe (Smiles: Verb)."

b) The second correct translation in Spanish:

"Sonríe (Smiles: verb) el niño (The kid: subject)."

c) The only correct translation in Brazilian-Portuguese:

"As crianças (the kid) sorriem (smiles: verb)."

d) Incorrect translation in Brazilian-Portugese:

"Sorriem (smiles: verb) as crianças (the kid)." 
In Spanish and Brazilian-Portuguese, the construction of a declarative sentence with an "unaccusative verb" does not follow the V2 rule. An unaccusative verb is a verb that does not initiate or is not actively responsible for the act of the subject as in the sentence "My friend died one year ago." The sentences are only considered grammatically correct if they do not follow the (V2) rule. By contrast, declarative sentences in English with "unaccusative verbs" always follow the ( $\left.\mathrm{V}_{2}\right)$ rule. This selected grammatical feature was considered to be a case of negative syntactic transfer from English into Brazilian-Portuguese. The examples below illustrate this case.

- Correct sentence in English: "My friend (subject) died (verb) one year ago (object)."

- Incorrect Sentence in English: "Died (verb) my friend (subject) one year ago (object)."

- Correct translation in Spanish: "Murió (died: verb) mi amigo (my friend: subject) hace un año (one year ago: object)."

- Incorrect translation in Spanish: "Mi amigo (my friend: subject) Murió (died: verb) hace un año (one year ago: object)."

- Correct translation in Brazilian-Portuguese: "Morreu (died: verb) meu amigo (my friend: subject) há um ano (one year ago: Object)."

- Incorrect translation in Brazilian-Portuguese: "Meu amigo (my friend: subject) morreu (died: verb) há um ano (one year ago: object)."

One of the two main tasks in this study was the "Grammaticality Judgment Test". This task examined participants' syntactic knowledge of word order in the composition of Brazilian-Portuguese declarative and interrogative sentences. In this task a number of selected sentences were presented in a written form, some of which were grammatically correct and others grammatically incorrect. Participants were asked to judge the grammaticality of each presented sentence. Participants were asked to correct sentences they believed were incorrect. The task included one hundred sentences of which forty were grammatically incorrect (the target features) twenty were grammatically correct and also included 40 "fillers".

Results showed that the amount of negative syntactic transfer from Spanish into Brazilian-Portuguese (transitive, intransitive verbs) was very similar between Group A $(M=29.5 \%)$ and Group B $(M=29 \%)$. The same amount of negative syntactic transfer occurred from Spanish into Brazilian-Portuguese whether Spanish was participants' L1 or L2. The main cause of the negative syntactic transfer was the typological dissimilarity between these two languages.

Results also demonstrated the amount of negative syntactic transfer from English into Brazilian-Portuguese (unaccusative verbs) was very similar between Group A $(\mathrm{M}=32 \%)$ and Group B $(\mathrm{M}=30 \%)$. The same amount of negative syntactic transfer occurred from English into Brazilian-Portuguese whether English was participants' L1 or L2. In this case the main cause of the negative syntactic transfer was the typological dissimilarity between these two languages. 
In summary, this section reported that in TLA the typological dissimilarity between languages is the main factor causing negative syntactic transfer from $\mathrm{L} 1$ and $\mathrm{L}_{2}$ into $\mathrm{L}_{3}$. This occurred in cases where participants' $\mathrm{L}_{3}$ level of proficiency is elementary.

\section{Learner's Linguistic Proficiency}

This factor relates to the learner's linguistic proficiency of their native and target languages. Learner's linguistic proficiency of a given language is equal to the sum of their "Implicit Linguistic Knowledge" (ILK) and "Explicit Linguistic Knowledge".

\subsection{Level of L1 Explicit Linguistic Knowledge}

This section investigates the impact of a learner's L1 ELK on syntactic transfer in TLA. Falk et al. (2015) investigated the relationship between L1 ELK and syntactic transfer in TLA. They defined "syntactic transfer" as an explicit phenomenon wherein L3 learners consciously select a "syntactic feature" from L1 or L2, for transfer into L3. They suggested that syntactic transfer primarily occurs from L2 into L3, rather than from L1, since L2 is learned explicitly. However, when $\mathrm{L}_{3}$ learners have an advanced L1 ELK, language transfers primarily occur from L1 to L3. In this case L1 becomes the main source of the syntactic transfer. Their study was designed to test their hypothesis as explained below.

To investigate the impact of the L1 ELK on syntactic transfer in TLA, Falk et al. (2015) recruited 45 participants. All participants had L1 Swedish and an L2 belonging to the Romance language family (Italian, Portuguese, or Spanish). Participants with L2 belonging to the Germanic language family were excluded. Participants had L3 Dutch at an elementary level. Before the study commenced, participants were enrolled in a Dutch language course at Stockholm University. Participants set the "Metalinguistic Knowledge Test" (MKT) which was designed to measure the ELK of their L1 Swedish. This test comprised sentences with a deliberate grammatical error. Participants had to provide a written description of the rule that the error was violating. Participants were divided into two groups. Group A $(n=16)$ had a low level of ELK in their L1 Swedish. Participants scored low on the "metalinguistic knowledge test" (MKT) in L1 Swedish $(M<60 \%)$. Group B ( $=24)$ had high ELK in L1 Swedish and scored high on the MKT (M > 70\%). Participants of both groups were proficient in their L2; they had high L2 ELK. Participants also sat the MKT in their L2 and all scored above 70\%. In summary, the only variable distinguishing the two groups was L1 ELK. Group A had a higher level of L1 ELK than Group B.

In this study, the grammatical target features selected to be investigated are described as follows. When constructing sentences in a Romance language the "colour adjective" usually follows the noun, as in the French sentence "J'ai acheté une voiture rouge" for which the English word-for-word translation is "I bought 
a car red". In contrast, when constructing sentences in a Germanic language the "colour adjective" is located before the noun. The Dutch sentence "Ik heb een rode auto gekocht" for which the English word-for-word translation is "I rent a red car" illustrates this point.

To examine the relationship between L1 ELK and syntactic transfer in TLA, participants had to complete two set tasks. In the first, participants were "given prompt cards with pictures illustrating Dutch verbs, along with the Dutch verb written on a different card. The participants had to match the words with the pictures, and produce the words orally in Dutch" (Falk et al. 2015: 231). In the second task, participants were set in pairs; every pair was required to make a deal for buying a dog. The agreement was to take place via communication in Dutch. Participants were handed a sheet wherein three dogs were drawn in three different colours (blue, red, and yellow). There was a caption under each picture in Dutch for which the English word-for-word description is: "happy red dog", "sad blue dog", and "angry yellow dog". Descriptions were used to help participants favour selection. Participants had to say which dog they wished to purchase in Swedish (for example, "We want to buy the red dog, happy dog"). From both tasks, a corpus of 239 adjectives were collected and examined.

Results showed that high L1 ELK seemed to increase the rate of "Positive Syntactic Transfer" from L1 to L3. These results were obtained by comparing the percentage of correctly placed adjectives between Group A and Group B. Both groups had a high level of L2 ELK; however, only Group A participants had a high L1 ELK. Group A had a significantly higher percentage of correctly placed adjectives than Group B $(M=59.94>M=44.12 ; p<0.005)$. Researcher thereafter postulated that a high L1 ELK can enhance positive syntactic transfer from $\mathrm{L}_{1}$ into $\mathrm{L}_{3}$.

In summary, this study suggested that a high level of L1 ELK could enhance positive syntactic transfer from $\mathrm{L}_{1}$ into $\mathrm{L} 3$.

\section{2. $L 2$ and $L 3$ level of proficiency}

This section investigates the impact of learners' $\mathrm{L}_{2}$ and $\mathrm{L}_{3}$ level of proficiency on syntactic transfer in TLA. A psycholinguistic model of $\mathrm{L}_{2} / \mathrm{L} 3$ proficiency would comprise both ELK and ILK of these two languages. In the studies that this paper is going to review, some of the research very clearly addresses the impact of learner's L2/L3 ELK on syntactic transfer in TLA, which was evident in learners' L3 ELK (e.g. Falk, Bardel 2011; Hermas 2015). Other studies reflect the impact of general L2/L3 level of proficiency on syntactic transfer in TLA. A transfer which was evident in learners' L3 general knowledge (ELK and ILK).

Studies that investigated the impact of $\mathrm{L}_{2}$ and $\mathrm{L}_{3}$ level of proficiency on syntactic transfer in TLA comprised two tasks. First task was the proficiency test sat prior to the commencement of the study determining participants $\mathrm{L}_{2} / \mathrm{L}_{3}$ level of proficiency. Second task was a grammar task to examine syntactic transfer in TLA. In order to determine if these two tasks addressed ELK, many factors should be taken into consideration. These factors include the absence of time pressure on 
tasks, certainty of answers provided and post-test interviews to record awareness by participants of conscious use of syntactic transfer from $\mathrm{L}_{1} / \mathrm{L}_{2}$ into $\mathrm{L}_{3}$ as a strategy in L3 use. This rationale was based on Ellis et al.'s (2009) definition of ELK as conscious linguistic knowledge, and his conclusion that for a test to measure ELK, the following five factors must be taken into account: 1) judgment accuracy, 2) certainty of judgment, 3) type of knowledge utilized in making the judgment, 4) learner's ability to correct an ungrammatical sentence, 5) time availability for answers. Where the research instruments took these factors into account, we can infer that the studies examined the impact of L2/L3 level of ELK and syntactic transfer in TLA, and this syntax transfer is evident in $\mathrm{L}_{3}$ ELK. This section also discussed the extent to which the design of these respective studies gauged the impact of $\mathrm{L}_{2} / \mathrm{L}_{3}$ level of proficiency on syntactic transfer on TLA rather than simply documenting the effect of $\mathrm{L}_{2} / \mathrm{L}_{3}$ proficiency on participants' accuracy of L3 syntactic production.

The following section will examine the impact of L2/L3 level of ELK on syntactic transfer in TLA, and also examine if this transfer was evident in participants' L3 ELK. In Hermas (2015), participants formed two groups. Group A had 11 Arabic native speakers with L2 French and L3 English. Group B comprised 15 Arabic native speakers with L2 French and L3 English. Group A participants had a post-intermediate level of L2 ELK and a pre-intermediate level of L3 ELK. Group B participants had a post-intermediate level of L2 ELK but had an advanced level of $\mathrm{L}_{3}$ ELK. The only variable differentiating these two groups was the level of L3 ELK. Group B participants had an advanced level of L3 ELK; in contrast, Group A participants had an elementary level of L3 ELK. Participants' L2 and L3 level of proficiency was determined by the Oxford Online Placement Test (OOPT). The OOPT examines the level of proficiency of all European languages. Participants sat the OOPT in both their $\mathrm{L}_{2}$ and $\mathrm{L}_{3}$. The digital OOPT is a standardized test from Oxford University. Learners' rating on OOPT is based on the Common European Framework of Reference for Languages (CEFR). There are two parts to the OOPT: writing and listening. The writing part comprises a lengthy written passage with gaps, and participants were asked to fill in these gaps. This task measures learners' ELK because it complies with Ellis et al.' (2009) conditions. Participants were given sufficient time, the task examines learner's ability to use metalinguistic knowledge, participants had to provide the accurate answer, and were asked to provide a certain correct answer on the basis that every incorrect answer will eliminate a correct answer.

The listening part of the OOPT comprises three tasks. In the first task, learners are presented with a number of short dialogues, in the second task learners are presented with a lengthier dialogue. In the third part, learners listen to a very lengthy monologue. In the three tasks learners must answer a multiple-choice question reflecting their understanding of the meaning for the information provided. The listening part of the OOPT determines learner's $\mathrm{L}_{2} / \mathrm{L}_{3}$ general level of proficiency because it examines learner's understanding of the general meaning of the linguistic input. In this OOPT, in order for a learner to have an upper-intermediate 
or advanced level of $\mathrm{L}_{2} / \mathrm{L}_{3}$ proficiency, they must show adequate proficiency in both the writing and the listening sections. Since the overall ranking in the OOPT is the lower of the two sections, the overall ranking can be taken as a ranking of Participants' L2/L3 ELK.

In Hermas' (2015) study the critical issue affecting the transfer from L1 Arabic or L2 French into L3 English is the difference in the way that Arabic and French treat "lexical complementisers" (C) in sentences that include an "unspecific indefinite subject" or "unspecific indefinite object". In English, relative pronouns (e.g. that, who) are sometimes referred to as "lexical complementisers" (C). They function as a "subordinating conjunction" to introduce a clause. In English and French when a sentence contains an "unspecific subject" it is only considered grammatically correct when a sentence includes a "complementiser" to introduce a "complement clause". The following grammatically correct English sentence illustrates this case "A boy (unspecific subject) that (C) saw the crime, was shocked (clause)." The correct French translation for the previous English sentence given as an example is "Un garçon (sujet indéfini) qui (C) a vu le crime choqué (clause)." By contrast, in Arabic a sentence that contains an "unspecific subject" is only considered grammatically correct when no "complementiser" is used. The English word-for-word translation for the grammatically correct Arabic sentence is the following "A boy $\varnothing$ (null C) saw the crime was shocked." This grammatical feature was selected to trace negative syntactic transfer from L1 Arabic into L3 English. This grammatical feature can also be a potential source of positive syntactic transfer from French into English. In this case positive transfer can be observed because an interview was held immediately after the test. In this interview participants have clearly explained that their use of syntactic rules was based on the similarity between their previous learned language and the target language. A critique of methods studying positive syntactic transfer is included later in this article.

In English and French when a sentence contains an "unspecific object" it is only considered grammatically correct if a "complimentizer" is used to introduce a "complement clause" as in the English sentence, "A Poem (indefinite object) that (C) John recited to the class was exciting (clause)." The correct French translation for the English sentence given above is "Un poème (indefinite subject) que (C) Jean réciter à la classe était existant (clause)." By contrast, in Arabic when a sentence includes an "unspecific subject" it is only considered grammatically correct when no "complementizer" is used to introduce a "complement clause". The English word-for-word translation for the grammatically correct Arabic sentence is "A Poem (unspecific subject) $\varnothing$ (null complimentizer) John recited to the class was exciting (clause)." This grammatical feature was also selected to trace negative syntactic transfer from L1 Arabic into L3 English. This grammatical feature can also be a potential source of positive syntactic transfer from French into English. In this case positive transfer can be observed because an interview was held after the test.

Participants took the "Acceptability Judgement Test" (AJT) in the English version. The task had 30 different sentences. Participants first indicated whether each 
presented item was grammatically correct. Then, they had to indicate the degree of certainty of their answer on a four-point scale varying from "certainly unacceptable" to "certainly acceptable". The construction of the sentences was based on the selected grammatical features. The AJT was not time-pressured. This task was followed by an interview. Participants were asked to declare if their answers were based on random choices or on their syntactic knowledge of previously learned languages. The purpose of the interview was to establish L1/L2 syntactic transfer into $\mathrm{L}_{3}$ in participants' answers.

Results on the accuracy of mean average scores for sentences that included both indefinite subjects and indefinite objects with a lexical complementizer was the following. Group A $(M=77.77 \%)$ scored higher than Group B (M=52.43\%). An interview was conducted to investigate the participants' knowledge on these two grammatical features. Group A participants reported that they depended mainly on their L2 French linguistic knowledge. Group B participants reported they mainly counted on their $\mathrm{L}_{3}$ linguistic knowledge. These results suggest that a high $\mathrm{L}_{3}$ level of proficiency may inhibit the participants' positive syntactic transfer from L2 into L3 syntactic production. However, participants with a low level of $\mathrm{L}_{3}$ proficiency may manifest positive syntactic transfer from L2 into L3 syntactic production.

In this study the AJT task provides an accurate means to test the effect of L2 and $\mathrm{L}_{3}$ level of ELK on syntactic transfer in TLA. This is because the test measured the degree of certainty of answers and only answers provided with a high degree of certainty were taken into consideration. Secondly, this task was not time-pressured. Thirdly, based on the answers provided by participants during the interview, it was clear that learners were consciously aware of using syntactic transfer from previously learned languages as a strategy to answer questions that included grammatical features they were unfamiliar with. Consistent with the rationale related to the design of a task used to measure ELK, this study showed the effect of L2/L3 level of ELK on syntactic transfer in TLA. However, asking students to provide the correct version of the ungrammatical sentences in this task would have made the test a more valid measure of ELK.

In summary, this study suggested that in TLA, participants with a high level of L3 ELK may inhibit positive syntactic transfer from a previously learned language. By contrast, participants with a low level of $\mathrm{L}_{3}$ ELK may promote positive syntactic transfer from previously learned languages. This occurred when participants' L2 level of ELK was post-intermediate.

Falk and Bardel (2011) investigated the effect of L2/L3 ELK on syntactic transfer in TLA. Participants in their study formed two groups. Group A ( $n=22)$ had L1 French, L2 English and L3 German. Participants in Group B $(n=25)$ had L1 English, L2 French and $\mathrm{L}_{3}$ German. Participants of both groups had an advanced $\mathrm{L}_{2}$ level of ELK and an intermediate $\mathrm{L}_{3}$ level of ELK. Participants' levels of proficiency were based on the OOPT in written form. The written OOPT evaluates proficiency in accordance with the Common European Framework of Reference (CEFR). The written OOPT addresses ELK, as it is similar in context to the digital OOPT. The examination was made by a certified CEFR-examiner (Division 2001). 
In this study a negative syntactic transfer can only take place from French into English in the placement of an object reflexive pronoun in sentences that include "main clauses". In this case the object placement is pre-verbal in French and postverbal in English and German. The examples provided below illustrate this rule:

Example 1. Placement of an object pronoun in the sentences that include "main clauses"

- German: "Ich (subject) erkenne (finite verb) ihn (object pronoun) ..." / English word-for-word translation: "I recognized him."

- English: "I recognized him ..." / subject, finite verb, object pronoun /

- French: "Je (subject) le (object pronoun) reconnais (finite verb) ..." / subject, finite verb, object pronoun / English word-for-word translation: "I him recognized".

In this study a negative syntactic transfer can only take place from English into German in the placement of object pronouns in sentences that include "subordinate clauses". In this case the object placement is pre-verbal in French and German and post-verbal in English. The examples provided below illustrate this rule:

Example 2. Placement of an object pronoun in the sentences that include "subordinate clauses"

- German: "Ich sehe, dass Nicolas sich verletzt hat ..." / English word-for word translation: "I see that Nicolas himself hurt."

- English: "I see that Nicolas hurt himself ..."

- French: "Je vois que Nicolas (subject) s' (object pronoun) est blessé (finite verb ...)" / English word-for-word translation: "I see that Nicolas himself hurt."

The researchers examined the placement of "object pronouns" in both "main" and "subordinate clauses" in a "Grammaticality Judgement Correction Task" (GJCT). The GJGT was composed of 144 German sentences of which 84 items were grammatically correct and the other 60 items were grammatically incorrect. For the grammatically incorrect sentences 30 represented cases of negative syntactic transfer from French into German (as in example 1) and the other half represented cases of negative syntactic transfer from English into German (as in example 2). In this task the sentences were presented in a written form and participants had to assess their grammaticality and correct the ungrammatical items. When participants did not know the true answers they were advised not to provide an answer. This task was not followed by an interview. Participants were not asked to declare if their answers were based on random choices or on their syntactic knowledge of previously learned languages. The GJCT takes into consideration the following three factors: judgment accuracy, certainty of judgment, learner's ability to correct an ungrammatical sentence. This study therefore investigated the effect of $\mathrm{L}_{2} / \mathrm{L}_{3}$ level of ELK on syntactic transfer in TLA.

Results showed that group B $(\mathrm{M}=17.9 \%)$ made more errors than group A $(\mathrm{M}=1.9 \%)$ pertaining the wrong placement of an "object pronoun" in the German sentences that included "main clauses". Falk and Bardel (2011) indicated that learners' grammatical mistakes were influenced by the negative syntactic transfer from French into German. 
This negative transfer occurred more when French was the participants' L2 than when French was their $\mathrm{L}_{1}(17.9 \%>1.9 \%)$. Results showed that group A $(\mathrm{M}=15.2 \%)$ made more errors than group B $(\mathrm{M}=3.9 \%)$ pertaining the wrong placement of an "object pronoun" in the German sentences that included "subordinate clauses". Researcher indicated that learners' grammatical errors was influenced by the negative syntactic transfer from English into German. This transfer occurred more when English was the participants' L2 than when it was the participants' $\mathrm{L}_{1}(15.2 \%>3.9 \%)$.

In sum, this study showed that when L1 and L 2 are typologically dissimilar from $\mathrm{L}_{3}, \mathrm{~L}_{2}$ is the main cause of negative syntactic transfer into $\mathrm{L}_{3}$. This occurred in cases where $\mathrm{L}_{3}$ level of ELK is intermediate and $\mathrm{L}_{2}$ level of ELK is advanced.

The correction phase in the task was established to examine positive syntactic transfer from L1 or L2 into L3. Each time students corrected the wrong placement of an object pronoun in German sentences that include "main clauses" this was interpreted as being a positive syntactic transfer from English into German. Every time students corrected the wrong placement of an object pronoun in the German sentences that included "subordinate clauses" this was interpreted as being a positive syntactic transfer from French into German.

Results showed that Group B participants performed better than group A participants. This concerned the correction of the wrong placement of an object pronoun in German sentences that include "main clauses" ( $M=28.8 \%>M=24.6 \%)$. Falk and Bardel (2011) indicated that learners' grammatical performance was influenced by the positive syntactic transfer from French into German. They stated that positive syntactic transfer from French into German was higher when French was the participants' L2 than when French was the participants' L1.

Results also showed that Group A participants performed better than group B participants. This concerned the correction of the wrong placement of an object pronoun in German sentences that include "subordinate clauses" ( $M=29.9 \%>M=18.96 \%)$. Falk and Bardel (2011) indicated that learners' grammatical performance was influenced by the positive syntactic transfer from English into German. They stated that positive syntactic transfer from English into German was higher when English was the participants' L2 than when English was their L1.

To conclude, a high level of $\mathrm{L}_{3}$ ELK may inhibit positive syntactic transfer from a previously learned language (Hermas 2015). By contrast, a low level of L3 ELK may promote positive syntactic transfer from previously learned languages (Hermas 2015). When $\mathrm{L}_{1}$ and $\mathrm{L}_{2}$ are typologically similar to $\mathrm{L}_{3}, \mathrm{~L}_{2}$ is the main facilitator of positive transfer into L3. This occurred in cases where learners' L2 level of ELK is advanced and their L3 level of ELK is intermediate (Falk, Bardel 2011). Similarly, when L1 and L2 are typologically dissimilar with $\mathrm{L}_{3}, \mathrm{~L}_{2}$ is the dominant source of negative syntactic transfer into $\mathrm{L}_{3}$. This occurred in cases where learners' $\mathrm{L}_{2}$ level of ELK is advanced and their $\mathrm{L}_{3}$ level of ELK is intermediate (Falk, Bardel 2011).

The following section will examine the impact of $\mathrm{L}_{2} / \mathrm{L}_{3}$ general level of proficiency on syntactic transfer in TLA. Bardel and Falk (2007) investigated negative syntactic transfer from $\mathrm{L}_{1}$ and $\mathrm{L}_{2}$ into $\mathrm{L}_{3}$ in an initial state of $\mathrm{L}_{3}$ acquisition (low level of $\mathrm{L}_{3}$ proficiency). 
Their study recruited five participants who were arranged into two groups. Group A comprised three participants, who spoke L1 Dutch, L2 English and L3 Swedish. Group B included two participants. One participant had L1 English, L2 Dutch and L3 Swedish. The other had L1 Hungarian, L2 Dutch, and L3 Swedish. All participants had an advanced L2 level of proficiency and a low L 3 level of proficiency. L2 and $\mathrm{L}_{3}$ level of proficiency was examined according to participants' self-estimation.

In the five languages investigated by the research (English, Hungarian, Dutch, German, and Swedish), the key factor influencing transfer from L1 or L2 into L3 pertained to the difference in how these languages treat negative patterns. In preverbal negation, the "negator" precedes the main verb, as is the case in Hungarian. In post-verbal negation, the "negator" follows the main verb, as is the case in Dutch, German and Swedish. In English, the "negator" comes between an auxiliary and the main verb. This creates a potential source of negative syntactic transfer from English and Hungarian into Swedish. The examples below illustrate how this can occur.

- English language: The child does (auxiliary) not (negator) speak (verb).

- Hungarian language: A gyerek (the child) nem (not: negator) beszél (speak: verb).

- Dutch language: Het kind (the child) spreekt (speak:verb) niet (not: negator).

- German language: Das Kind (the child: subject) spricht (speaks; verb) nicht (not: negator).

- Swedish language: Barnet (the child) talar (speaks) inte (not: negator).

All participants $(n=5)$ were enrolled in a Swedish language course of 4 months duration at the University of Nijmegen in the Netherlands. All lessons were video-taped and audio-recorded. This allowed the researcher to trace the syntactic feature and to report results. Researchers made a transcript for the recordings documenting all errors pertaining to the use of "negative patterns" in participants' L3 Swedish syntactic production. Group A participants $(\mathrm{n}=3)$ had L1 Dutch and L2 English. In Group B $(n=2)$, one participant had L1 English and the other had L1 Hungarian; both had L2 Dutch. Comparing negative syntactic transfer between these two groups enabled researchers to determine whether negative syntactic transfer occurred more frequently from L1 or from L2 in participants' L3 Swedish syntactic production. An aural productive task was used to monitor student aural linguistic behaviour concerning the grammatical feature examined. This task did not address ELK for the following reasons. Learner's ability to correct an ungrammatical sentence was not examined. Learners did not make any grammatical judgment of accuracy over any presented input nor were able to show the certainty over their grammatical decision.

Results showed that Group A participants made 81 errors in their Swedish L3 syntactic production of "negative patterns". This can be the result of negative syntactic transfer from L2 English into L3 Swedish. English and Swedish differ in how they treat the grammatical feature of negative patterns. Researchers stated that in the initial stage of Swedish L 3 acquisition, when English L2 level of proficiency is advanced, L2 has a high syntactic negative transfer effect on $\mathrm{L}_{3}$ syntactic oral production. 
Results also showed that Group B participants made 54 errors in their Swedish L3 syntactic production of "negative patterns". Researchers stated that in the initial stage of Swedish L3, L1 (Hungarian or English) has a considerable syntactic negative transfer effect on $\mathrm{L}_{3}$ syntactic production. This occurred because participants L1 (Hungarian or English) and $\mathrm{L}_{3}$ Swedish differ in how they treat the grammatical feature of "negative patterns".

By comparing the two Group results (Group A, errors $=81>$ Group B, errors $=54$, $\mathrm{p}<0.01$ ) the researchers found that in cases where the $\mathrm{L}_{2}$ is typologically dissimilar to the $\mathrm{L}_{3}$, there are more cases of negative syntactic transfer than in cases where $\mathrm{L}_{1}$ is typologically dissimilar to $\mathrm{L}_{3}$.

In summary, this study showed that in the initial stage of $\mathrm{L}_{3}$ acquisition and when L2 level of proficiency is advanced, L2 has a higher syntactic negative transfer effect than L1 on L3 syntactic oral production. This occurred when participants' $\mathrm{L}_{3}$ level of proficiency was low.

\section{Individual Factors}

Individual differences among learners such as age, attitude and cognitive ability influence the likelihood of syntactic transfer in SLA (Ellis 2015). In TLA, learners' age and attention control are the factors that was found to influence $\mathrm{L}_{1} / \mathrm{L}_{2}$ syntactic transfer into $\mathrm{L}_{3}$.

\subsection{Age}

Flynn et al. (2004) investigated the role of age in determining syntactic transfer in TLA. This study recruited two groups of participants comprising different age groups. Group A were adults $(n=33)$ aged over 18. Group B consisted of children $(n=30)$ whose age was between 10 and 12. All participants had L1 Kazakh, L2 Russian and L3 English. The L3 level of proficiency for all participants was elementary. Participants' L2 level of proficiency varied. Groups A included learners with low $(n=7)$, intermediate $(n=14)$ and advanced $(n=12)$ levels of L2. Groups B included learners with low $(n=10)$, intermediate $(n=12)$ and advanced $(n=9)$ levels of L2. The Michigan English Test (MET) was used to assess participant's level of $\mathrm{L}_{3}$ proficiency. This test concerns listening, grammar and speaking. The MET for listening and grammar includes one hundred multiple-choice questions. The MET for speaking proficiency was a structured, oneon-one interaction between the examiner and student. The study did not mention the specific task used to evaluate the L2 level of proficiency though it claimed that participants sat the adequate test to evaluate their L2 level of proficiency. However, because Flynn et al. (2004) failed to describe the task used to measure participants' L2 level of proficiency included in this test, their contention cannot readily be critiqued.

Russian is a "right branching" Slavic language with "subject, verb, object" word order and has a similar word order to English which is also a "right branching" Indo-European language. There are three grammatical features common to both 
languages, in which when constructing a sentence, the "relative clauses" appears to the right of the noun (subject/object). The three grammatical features are the following: a) lexically headed clause with semantic content; b) lexical headed clause with no semantic content and c) "free relative clause". By contrast, Kazakh is a left branching language in which relative clauses are positioned to the left of their nouns (subject/object). These grammatical structures constitute a potential source of negative syntactic transfer from L1 Kazakh into L3 English.

A "relative clause" is considered to be a "lexically headed clause with semantic content" only if its "relative pronoun" refers to a specific noun (subject/object). This specific noun is valuable in semantic terms (as having a reference, a sense, and some truth values). The following example in English illustrates the case: "I met Bernie (specific noun) [who (relative pronoun) became my best friend] (relative clause)." By contrast a "relative clause" is considered "lexically headed with no semantic content" only if its "relative pronoun" refers to a nonspecific noun (subject/object). The following example illustrates the case: "The janitor criticized the person (noun) [who (relative pronoun) called the lawyer] (relative clause)." A relative clause which does not include a noun (subject or object) to which usually a relative pronoun refers is considered to be a "headless relative clause". The following example illustrates the case: "[whoever (relative pronoun) spoke against the totalitarian president was executed] (relative clause)." The noun in the given example is syntactically presented but phonologically and orthographically empty. A free relative clause, is also known by the term "headless relative clause". The above-mentioned similarities between L2 Russian and L3 English may create a potential positive syntactic transfer between these two languages. Table 1 below illustrates the syntactic differences and similarities in Russian, English, and Kazakh.

Participants sat an "elicited imitation" test in which they listened to twelve English sentences and were asked to imitate each sentence. Students were not restricted by time. Sentences in this study reflect three syntactic target features. Each was presented in four sentences. The three target features as described before were: (a) lexical head with semantic content; (b) lexical head with no semantic content and (c) "free relative".

Results showed that Group A (adults) scored higher than Group B (children) (M 66\% > 32\%). A greater amount of negative syntactic transfer occurred among young learners. This suggests young learners were possibly consciously drawing on dissimilarities between their $\mathrm{L}_{1}$ and $\mathrm{L}_{3}$. The researcher postulated that young learners are more affected by the typological dissimilarities between $\mathrm{L}_{1}$ and $\mathrm{L}_{3}$ and that negative syntactic transfer from $\mathrm{L}_{1}$ into $\mathrm{L}_{3}$ may occur more frequently among young learners than old learners.

The methodology of the study did not fully control for $\mathrm{L}_{3}$ amount and exposure. The following explanation will justify the case. Group A and B included participants with three different levels of proficiency (low, intermediate, advanced). A comparison between the performances of these two groups was made in order to understand the effect of age on syntactic transfer in TLA. However, a superior methodology would entail the comparison of each category of proficiency between counterparts in the other pair. For example, a comparison of the performance of young learners with intermediate $\mathrm{L} 2 / \mathrm{L} 3$ proficiency could be made with their older counterparts in 





Group B who have a similar level of $\mathrm{L}_{2} / \mathrm{L} 3$ proficiency. It is also of crucial importance that the two groups compared have received the same amount of $\mathrm{L}_{3}$ instruction, as this will help to more accurately reflect the effect of age on facilitating transfer by isolating the effect of other factors.

In their longitudinal study, Pfenninger and Singleton (2016) examined the degree in which the "Starting Age" and the "amount of $\mathrm{L}_{3}$ exposure" can impact negative syntactic transfer from L1 and L2 into L3. "Starting Age" refers to the age from which a bilingual student begins to learn their third language.

In their study, participants formed two groups. Group A ( $\mathrm{n}=100)$ had L1 German, L2 French and L3 English. They studied German from the 1st grade onwards, English from the 2nd grade and French from the 5th grade. As French is one of the Swiss national languages, learners are exposed to more French in daily life than English. Swiss students are usually more proficient in French than English, despite that learners start to learn English at school before French. On this basis, French was considered to be participants' L2 language and English their L3. Group A participants were taught foreign languages in accordance with the new guidelines issued by the Swiss Minister of Education. For Group B ( $n=100)$ participants had L1 German, L2 French and L3 English. They studied German from the 1st grade, French from the 5th grade and English from the 7 th grade. Group B participants studied L 3 English in accordance with the old curriculum. There were two differences between participants of the two groups: starting age and amount of $\mathrm{L}_{3}$ exposure. Group A participants began learning L 3 English in primary school whereas Group B students only commenced learning L 3 English in secondary school. Data collection took place after all students finished Grade 12. Group A participants received 1120 hours of English instruction. By contrast Group B participants only received 730 hours of English instruction. Group A participants therefore had 390 additional hours of instruction in primary school. The study did not indicate any difference in the style of teaching between the old and the new curriculum.

The key factor influencing transfer from L1 German into L3 English pertained to the difference in how these languages treat negative patterns. In post-verbal negation the "negator" follows the main verb, as is the case in German. In French and English, the "negator" comes between an auxiliary and the main verb. Negative syntactic transfer from L1 German into L 3 English entailed the incorrect placement of finite verb in a declarative negative sentence. The examples below illustrate the case.

- English language: The child does (auxiliary) not (negator) speak (verb).

- French language: L'enfant (the child) ne (negator) parle (speak verb) pas.

- German language: Das Kind (the child: subject) spricht (speaks; verb) nicht (not: negator).

Another grammatical feature was also examined. A potential negative syntactic transfer (morpho-syntactic) from L1 German into L3 English also included the difference in the usage of the agentive suffix -er with singular and plural nouns. In both German and English adding an "Agentive Suffix" to the verb will turn it into a noun 
(sing: singer / säng: Sänger). In English the letter 's' must be added to the agentive suffix -er to turn the singular noun into its plural version (singer: singers). This is not the case in the German language as both singular and plural nouns terminate with only the "Agentive Suffix" (singers, Sänger).

Participants were asked to write two essays in English, one argumentative and one narrative. For the argumentative essay participants were asked to explicitly aurally describe the advantages and disadvantages of a TV show (talent show). In the narrative essay participants were asked to write in a narrative style describing a silent movie they had viewed. Participants were also asked to undertake two oral tasks in English (re-telling and spot-the-difference tasks). For the re-telling task participants were requested to orally describe the "silent movie" that they had previously watched. In the second oral task participants were put into pairs and asked to describe the differences between pictures that contained a number of overlapping scenes.

Results of the first task (oral task) showed that participants of both Groups A and B made errors. These errors pertained to their Swedish $\mathrm{L}_{3}$ syntactic production of "negative patterns". These errors also pertained to participants not adding an $s$ to the agentive suffix -er with plural nouns in their L3. Errors occurred with a mean of $17 \%$ for Group A participants and a mean of $19 \%$ for Group B participants. Pfenninger and Singleton (2016) postulated that these errors are the result of negative syntactic transfer from L1 German into L 3 English.

Results of the second task (oral task) showed that participants of both groups A and B made errors. These errors pertained to their Swedish L3 syntactic production of "negative patterns". These errors also pertained to participants not adding an $s$ to the agentive suffix -er with plural nouns in their L3. Errors occurred with a mean of $80 \%$ for Group A participants and a mean of $83 \%$ for Group B participants. Pfenninger and Singleton (2016) suggested that these errors are the result of negative syntactic transfer from L1 German into $\mathrm{L}_{3}$ English. They believed that in both tasks Group A participants performed better than group B participants because participants of group A had an extra 450 hour of Swedish L3 instruction, and they had started learning L3 earlier than participants of Group B.

Overall, this review found no solid evidence in Pfenninger and Singleton's study reflecting the degree to which the "amount of instruction" and "starting age" impacted syntactic transfer in TLA. The small difference in results could simply be related to $\mathrm{L}_{3}$ linguistic input. Furthermore, the methodology of this study does not completely differentiate between the effect of two separate causative factors influencing $\mathrm{L}_{3}$ learning ability, namely the amount and timing of $\mathrm{L}_{3}$ exposure. Hence one could draw an alternative interpretation of the results, being that the amount of $\mathrm{L}_{3}$ exposure was the variant accounting for the slight discrepancy of results between the two groups as opposed to the age at which participants began studying their L3.

In summary, this section argued that $\mathrm{L}_{3}$ adult learners are more aware of - and can exploit - typological similarities between L2 and L3 whereas children may depend more on their L1 in their $\mathrm{L}_{3}$ syntactic production. This section also showed that early $\mathrm{L}_{3}$ learning with a considerable amount of $\mathrm{L}_{3}$ instruction may help $\mathrm{L}_{3}$ learners in inhibiting negative syntactic transfer from L1 and L2 into L3. 


\subsection{Attention control}

Sanchez and Bardel (2016) examined the role of $\mathrm{L}_{3}$ learners' cognitive ability in inhibiting negative syntactic transfer from L 2 into $\mathrm{L}_{3}$. Their study of cognitive ability included the factors of "working memory ability", "attentional control ability" and "attention switching ability". This review only investigates the "attention control" factor as only this was found to have a significant influence on the amount of negative syntactic transfer in TLA by Sanchez and Bardel (2016).

Participants formed two groups. Both Group A $(n=27)$ and Group B $(n=20)$ had L1 Spanish, L2 German and L3 English. All participants had an advanced L2 level of proficiency but an intermediate $\mathrm{L}_{3}$ level of proficiency. Proficiency was also examined, based on the Online Oxford Placement Test. Group B participants had a higher "Attention Control Ability" than Group A. "Attention Control Ability" is defined as the capability of a learner of a new language to select linguistic features appropriate to the $\mathrm{L}_{3}$ from previously learned languages by utilizing all the available attention units in their mind. This was determined by the so called "Trail Making Test". The "Trail Making Test" comprises 25 circles, each representing a number. These circles are randomly distributed on paper and participants are asked to draw a line connecting all the circles in ascending sequential order by joining numbers from 1 to 25 . Results showed that participants in Group B were faster at accomplishing this task ( $M=42.63$ seconds $>M=24.76$ seconds). Accordingly, Group B participants had a higher "Attentional Control Ability" than Group A participants.

In the English and Spanish languages the object post-locates the finite verb in sentences constituting of "main clauses" or "embedded clauses" with an "auxiliary verb". By contrast, in German and under the same grammatical conditions the "object" is located between the "finite verb" and the "past participle". This constitutes a potential negative transfer from German into English. Examples 1 and 2 below illustrate the case.

Example 1. Case of sentence with a "main clause" and an auxiliary verb in English, Spanish and German

- English language: Nicolas (subject) has (finite verb) read (past participle) the book (object).

- Spanish language: Nicolas (subject) ha (has: finite verb) leído (read: past participle) el periodico (the newspaper: object).

- German language: Nicolas (subject) hat (has: finite verb) die Zeitung (the newspaper: object) gelesen (read: past participle).

Example 2. Case of sentence with an "embedded clause" and an auxiliary verb in English, Spanish and German

- English language: The man (subject) with green eyes (embedded clause) has bought (finite verb) the newspaper (object).

- Spanish Language: El hombre (the man: subject) de ojos verdes (with green eyes: embedded clause) ha comprador (has bought: the finite verb) el periódico (the newspaper: object). 
- German Language: Der Mann (the man: subject) mit den grünen Augen (with green eyes: embedded clause) hat (has: finite verb) die Zeitung (the newspaper: object) gekauft (bought: past participle).

In the English and Spanish languages, the object post-locates the finite verb in sentences which are composed of a "main clause" or an "embedded clause" with a modal verb. By contrast, in German and under the same grammatical conditions the "object" is located between the "infinite verb" and the "modal verb". In this study syntactic differences across related languages constituted a potential source of negative syntactic transfer from German into English. Examples 3 and 4 below illustrate the case.

Example 3. Case of sentence with a "main clause" and a modal verb in English, Spanish and German

- English language: Nicolas (subject) should (modal verb) read (finite verb) the journal (object).

- Spanish language: Nicolás (Nicolas: subject) debería (should: modal verb) leer (read: finite verb) la revista (the journal: object).

- German language: Nicolas (subject) sollte (should: modal verb) die Zeitschrift (the journal: obejct) lesen (read: infinite verb).

Example 4. Case of sentence with an "embedded clause" and a modal verb in English, Spanish and German

- English language: That man (subject) with red hair (embedded clause) should buy (finite verb) the car (object).

- Spanish language: Ese hombre (that man: subject) con el pelo rojo (with red hair: embedded clause) debe comprar (should buy: finite verb) el automóvil (the car: object).

- German language: Dieser Mann (Subject) mit roten Haaren (with red hair: embedded clause) sollte (should) das Auto (the car: Object) kaufen (infinite verb).

Researchers collected data by asking participants to listen to a narrative task describing Charles Chaplin's silent film "Modern Times". The narration was simultaneously accompanied by extracted photographs from the film. These photographs produced visual stimuli to help participants understand the meaning of the film. Once the scenes and the narration were delivered, participants were asked to write a complete summary of the story. All participants had previously studied the grammatical features tested in their previously learned language, but these features were unknown to them in their $\mathrm{L}_{3}$ linguistic knowledge. This enabled the researchers to determine the factor of attention control in prohibiting negative syntactical transfer.

Research found that Group A participants made less errors than Group B participants pertaining to the use of the syntactical feature examined in this study $(\mathrm{M}=41 \%<\mathrm{M}=60 \%)$. The difference in performance between participants of these two groups was statistically significant $(\mathrm{p}=0.049)$. Based on these results, Sanchez 
and Bardel (2016) stated that less negative syntactic transfer from L2 English into L3 Spanish occurred more among Group B participants than among Group A participants. Researchers stated that the high "Attention Control Ability" of Group A participants made them perform better than group B participants. Group A participants made fewer negative syntactical transfers from their L2 in comparison with Group B participants.

In sum, this section suggests that a high "Attention Control Ability" in $\mathrm{L}_{3}$ learners will allow them to inhibit negative syntactic transfer from L2 into L3.

\section{Psycholinguistic factors}

These are the factors "relating to the learners' perception about the transferability" (Ellis 2015: 121). In a TLA context, this is the transferability of L1/L2 syntactic features into L3 syntactic production. In TLA, psychotypological similarities across relevant languages constitute a factor that influences syntactic transfer in TLA.

\subsection{Psychotypology}

This section investigates the role of psychotypology in syntactic transfer in TLA. Psychotypology does not refer to the actual similarity or difference between languages, but rather to learner's perception of such similarities or differences (Ellis 2015).

Rothman's (2010) study also examined the role of psychotypology in syntactic transfer in TLA. His way of investigating learners' perception was based on asking participants to elicit which particular grammatical structure they favour, out of some given alternatives.

As previously noted, participants formed two groups. Group A $(n=15)$ had L1 Spanish, L2 English and L3 Brazilian-Portuguese (BP). Group B ( $\mathrm{n}=16)$ had L1 English, L2 Spanish and L3 BP. Rothman's (2010) study applied a "choice matching task" to understand the role of psychotypology in syntactic transfer in TLA. The task comprised ten sentences in BP. These sentences were designed to include an ambiguous clause which can result in multiple interpretations in terms of selecting the subject. The ambiguity of the ten sentences occurs as a result of there being two potential subjects. Both subjects pre-locate the finite verb. However, one is located at the beginning of the sentence (the first subject) and one is closer to the finite verb (the second subject). This is illustrated by the example below (sentence with an ambiguous relative clause). Both answers a) and b) are correct; some participants will favour answer a), the others will favour b). The motive behind their preferred choice will be explained after the example.

Sentence example: Last week I saw the mother of my husband who after the separation treated me unfairly.

- Question: Who treated me poorly?

- Possible answers: 
a) The mother of my husband

b) My husband

c) Not sure

d) Participants who are influenced by Spanish will choose answer b).

Rothman (2010) believes that participants who are influenced by Spanish as one of their previously learned languages will choose answer a). His rationale was based on previous research which found that participants who favour the first subject ("the mother of my husband") do so because they believe that Spanish is more typologically similar to Brazilian-Portuguese than English. These participants consciously or subconsciously favoured selecting the subject that is the most distant from the finite verb (the first subject). This bias arises from a belief that Spanish does not always follow the V2 Rule (Subject, Verb, Object) and the subject can be located far from the finite verb (see Gibson et al. 1996; Dussias 2004).

Rothman's (2010) believed that participants who are influenced by English as one of their previously learned languages will choose answer b). His viewpoint was based on previous research which found that participants who favour the second subject ("the husband") do so because they believe that English is more typologically similar to Brazilian-Portuguese than Spanish. These participants are consciously or subconsciously familiar with selecting the second subject that is located closer to the finite verb. This bias arises from participants' belief that English usually follows the (V2) Rule (Subject, Verb, Object) and the subject cannot be located far from the finite verb (Gibson, Pearlmutter 1998; Miyamoto 1998; Carreiras, Clifton 1999).

The two groups had the following scores: Group A and B both selected the first subject $70 \%$ of the time. Spanish language influenced their answers more than English. This occurred whether Spanish was participants' L1 or L2. In an interview that took place after the test, participants stated that their answers were influenced by their linguistic knowledge of Spanish. They believed that Spanish is closer to Brazilian-Portuguese than English in regard to the grammatical feature tested. Researchers interpreted the results as signifying that the psychotypological similarity between Spanish and Brazilian-Portuguese has influenced the positive syntactic transfer between these two languages. This transfer occurred in cases where Spanish was participants' L1 or L2.

There is scope to improve this research methodology by requesting participants report the reason for their choices following each of their answers. This methodology is likely to provide a more accurate insight than the post-test interview. After the conclusion of the test - and when providing general feedback to researchers - participants may be unable to fully recall what influenced their decisions in answering each and every sentence. This will not be the case if participants reported their choice after each and every answer.

In summary this section showed that positive syntactic transfer from $\mathrm{L}_{1}$ and $\mathrm{L}_{2}$ into L3 does not only depend on actual typological similarity across related languages but can also be influenced by a learner's perception of their similarity. 


\section{Other factors}

In TLA the amount of L2 exposure was found to influence $\mathrm{L}_{1} / \mathrm{L}_{2}$ syntactic transfer into L3. The following section will investigate this factor.

\subsection{L2 type and amount of instruction}

This section will investigate the impact the amount of L2 linguistic exposure has on syntactic transfer in TLA.

Stadt, Hulk, and Sleeman (2018) investigated the effect of L2 amount of "exposure and instruction" on negative syntactic transfer in TLA. Fifty-four native Dutch speakers participated in this study and they formed two groups. Group A participants $(n=16)$ had a great amount of L2 English linguistic exposure. They were third-year secondary school students enrolled in an "immersion school program". Participants in Group B ( $n=11)$ had a low amount of L2 English linguistic exposure. They were also third year secondary school students but were enrolled in a "regular" school program. In the Netherlands, the so called "immersion school program" entails teaching 50\% of the curriculum units in English and the remainder in Dutch. By contrast, in Dutch schools that have a "regular" school program, English is taught as a separate subject for an average of six hours per week. Participants in both groups had a high level of L2 proficiency but only Group A participants had a high amount of $\mathrm{L}_{2}$ exposure.

The critical issue affecting transfer from $\mathrm{L}_{1}$ or $\mathrm{L}_{2}$ into $\mathrm{L}_{3}$ is the difference in which English, French and Dutch treat the construction of sentences, including "adverbs of frequency". In Dutch and English, the "finite verb" is placed after both the "subject" and the "adverb of frequency". By contrast, in French language the "finite verb" is placed immediately after the "subject" and before the "adverbs of frequency". The examples provided below illustrate this rule:

- English sentence: Nicolas (subject) sometimes (adverbs of frequency) goes (finite verb) to the city.

Structure of the sentence: subject, adverb of frequency, finite verb.

- Dutch sentence: Nicolas (subject) soms (adverbs of frequency) gaat (finite verb) naar de.

English word for word translation: Nicolas sometimes goes to the city.

Structure of the sentence: subject, adverb of frequency, finite verb.

- French sentence: Nicolas (subject) va (verb) parfois (adverb of frequency) au ville.

English word for word translation: Nicolas goes sometimes to the city.

Structure of the sentence: subject, finite verb, adjective of frequency.

Researchers looked to the verb placement in the aforementioned grammatical feature. They collected data via a "grammaticality judgment task" in which 234 sentences were orally presented to students. All the sentences were grammatically incorrect. Students were asked to judge the grammaticality of the sentences presented by 
clicking "yes" or "no" buttons. The task was not timed and participants were not asked to correct the ungrammatical sentences.

Results demonstrated that Group A made fewer errors than Group B pertaining to the placement of finite verb in sentences with "adverbs of frequency". Group A participants' average of errors was $\mathrm{M}=5.93 \%, \mathrm{SD}=\mathbf{2 . 2 3}$. Group B participants' average of errors was $\mathrm{M}=3.8 \%, \mathrm{SD}=2.82$. The difference in results was significant with $\mathrm{p}=0.003$. Stadt et al. (2018) interpreted the results by declaring that Group A made more errors than Group B because Group A had a moderately significantly higher amount of negative syntactic transfer than Group B from $\mathrm{L}_{2}$ into $\mathrm{L}_{3}$, resulting from a higher amount of L2 exposure. Researchers also recruited two different groups of Year 4 students with different levels of L2 exposure. Participants were given the same task. Results also reported that there was a greater amount of negative syntactic transfer from $\mathrm{L}_{2}$ into $\mathrm{L}_{3}$ in the group that had a higher amount of $\mathrm{L}_{2}$ exposure and instruction. This study claimed to investigate the effect of L2 exposure on syntactic transfer in TLA. However, it only specifically considered the amount of L2 exposure through the medium of instructed learning, though language exposure can also occur from the language environment and other channels such as electronic media. Furthermore, Group A differed from Group B not only in the amount of L2 exposure and instruction, but also in the type of L2 exposure. Group A was exposed to both general English and academic English, as half of the curriculum units in the immersion school program were taught in English.

This study suggested that in TLA, an increase in the amount of L2 exposure through the instruction of general and academic usage may increase the rate of negative syntactic transfer from $\mathrm{L}_{2}$ into $\mathrm{L}_{3}$.

\section{Discussion}

This review led to the finding that in TLA, negative syntactical transfer depends on typological dissimilarities across related languages (L1, L2) with L3. Positive syntactical transfer in TLA, however, relies on typological similarities across related languages ( $\left.\mathrm{L}_{1}, \mathrm{~L}_{2}\right)$ with $\mathrm{L}_{3}$. Accordingly, typological proximity (linguistic factor) appears to be the necessary condition for the transfer phenomena to occur rather than a mere influential factor.

It seems that typological proximity as a factor on its own would have little impact on positive syntactical transfer in TLA if learners have no perception of it. It was found that positive syntactic transfer from $\mathrm{L}_{1}$ and $\mathrm{L}_{2}$ to $\mathrm{L}_{3}$ does depend both on the actual typological similarities across related languages with $\mathrm{L}_{3}$ and learners' perception of these similarities (psychotypology/psycholinguistic factor) (Rothman 2010). This review uncovered a knowledge gap regarding the influence of "psychotypology" on negative syntactical transfer in TLA. It is therefore recommended that future research be undertaken to close this knowledge gap. This could be attempted by applying a "similar" methodology to that which was developed by Rothman (2010) but for this purpose it must be used to examine negative syntactical transfer in TLA. 
This can be done by including grammatical items that reflect on negative syntactical transfer from $\mathrm{L}_{1} / \mathrm{L}_{2}$ into $\mathrm{L}_{3}$.

Furthermore, with the syntactic transfer being a mental phenomenon, its occurrence should also depend, to a high degree, on participants' cognitive abilities (individual factor). Sanchez and Bardel (2016) found that a high "Attention Control Ability" in $\mathrm{L}_{3}$ learners allowed them to inhibit negative syntactic transfer from L2 to L3. In their study, Group A participants had a more considerable "Attention Control Ability" than Group B participants. This ability concerns all languages. One could argue that learners with high cognitive abilities may also be able to make use of typological similarities across related languages with their $\mathrm{L}_{3}$. Future research to validate this consideration is recommended. It is worth noting that cognitive ability is not only limited to "attention control", but it can also include many other factors such as learners' a) working memory ability, b) attentional control ability, and c) attention switching ability.

One of the questions that this paper illustrated relates to which language, L1 or L2, is more influential on L3 syntactical production. Rothman (2010) gave equal importance to $\mathrm{L}_{1}$ and $\mathrm{L}_{2}$ in terms of their influence on negative syntactical transfer in TLA. However, Falk and Bardel's (2011) findings showed L2 as the main generator of negative syntactical transfer in TLA. One could argue that one of the primary differences between Rothman's (2010) and Falk and Bardel's (2011) studies were the participants' level of L2 proficiency: intermediate in Rothman's (2010) study and advanced in Falk and Bardel's (2011) study. From this, one can conclude that "L2 level of proficiency" (linguistic factor) can be a critical factor in syntactic transfer in TLA. Aligned with this, Pfenninger and Singleton's (2016) study found that an increase in the amount of $\mathrm{L}_{2}$ exposure through the instruction of general and academic usage may increase the rate of negative syntactic transfer from $\mathrm{L}_{2}$ to $\mathrm{L}_{3}$.

Knowing that "L2 level of proficiency" is an influential factor in syntactical transfer in TLA one should examine the magnitude of this influence when L2 participants' level of proficiency is relatively close to L1. It may be difficult to recruit participants meeting this criterion, mainly as L 2 in many cases, is acquired as a foreign language. However, one of the proposed solutions could be by selecting participants with an L2 that was acquired simultaneously with L1 from an early age. An example of such a jurisdiction is afforded by Switzerland, whose residents are formally instructed in two languages (such as Swiss-German and French) from an early age. To investigate this phenomenon, it is preferable to recruit participants who had received formal academic instruction in their L2. Such participants will have both explicit and implicit linguistic knowledge (ELK, ILK) in their L2. This will ensure participants' L2 linguistic knowledge approximates their L1 proficiency.

One factor that can enhance or prohibit syntactical transfer in TLA is the level of L3 proficiency (linguistic factor). If a student has an elementary level of proficiency in $\mathrm{L}_{3}$, they will rely on their previously learned languages when communicating in $\mathrm{L}_{3}$ because students are left without other options. In contrast, when students have a high level of $\mathrm{L}_{3}$ proficiency, they perform better in $\mathrm{L}_{3}$; however, they may still be exposed to both positive and negative syntactical transfer from their previously learned languages. 
Hermas (2015) found that a high level of L3 ELK may inhibit positive syntactic transfer from $\mathrm{L}_{2}$ to $\mathrm{L}_{3}$. He also found that a low level of $\mathrm{L}_{3}$ ELK may promote positive syntactic transfer from L2 to L3. Future research addressing negative and positive syntactical transfer from $\mathrm{L}_{1} / \mathrm{L}_{2}$ to $\mathrm{L}_{3}$ in cases where participants' level of proficiency in $\mathrm{L}_{3}$ varies (low/intermediate/high) is recommended. This will help to illustrate the influence of $\mathrm{L}_{3}$ level of proficiency on syntactical transfer in TLA.

Garcia Mayo and Slabakova (2015) argued that in specific cases, trilinguals are more exposed to syntactical transfer than bilinguals. This is because in TLA, there are two potential sources of transfer ( $\mathrm{L}_{1}$ and $\mathrm{L}_{2}$ ) in contrast to one possible source (L1) in the case of Second Language Acquisition (SLA). In their study, three groups were recruited: two groups of trilingual participants and one group of bilingual participants. They examined the amount of negative syntactic transfer between trilingual groups (A and B), on the one hand, and bilingual group (C), on the other. The results demonstrated that participants of Groups A and B were more subjected to negative syntactical transfer than participants of Group C. Their research suggested that the amount of negative syntactical transfer in the process of learning a new language might depend on the number of previously learned languages. This is true in cases where typological dissimilarities across related languages and L3 apply. These results provided further evidence that the discipline of TLA should be investigated independently and not considered similar to SLA. Future research should investigate this in the context of positive syntactical transfer in TLA.

Another point that this review discussed concerns the nature of syntactical transfer in TLA: explicit (conscious) and implicit (unconscious) phenomena. Falk et al. (2015) argued that the nature of a positive syntactical transfer is explicit. He believes that participants, in most cases, are self-determined and conscious in selecting grammatical rules from previously learned languages ( $\mathrm{L}_{1}$ and $\mathrm{L}_{2}$ ) and use them consciously in the syntactical production of $\mathrm{L}_{3}$. He suggested that participants' level of L1 ELK (linguistic factor) is a critical factor that influences syntactic transfer in TLA. His study recruited two groups of participants who only differed in terms of their L1 level of ELK. He found that the group with a high level of L1 ELK generated a more significant amount of positive syntactical transfer from L1 to L3. Future research should investigate the influence of L1 ELK on negative syntactical transfer in TLA, to close this knowledge gap.

Contradictory to Falk et al.'s (2015) hypothesis that syntactic transfer is an explicit phenomenon, Flynn et al. (2004) argued that negative syntactic transfer in TLA can also occur implicitly. This can be examined if one can find evidence of the occurrence of syntactical transfer from $\mathrm{L}_{1}$ to $\mathrm{L}_{3}$ among trilingual children (before the age of maturity). This is because children's knowledge of their $\mathrm{L} 1$ is mainly implicit, resulting from early implicit learning. Flynn et al. (2004) recruited two groups of participants comprising participants belonging to different age groups. The only variable that differed among the participants was "age" (individual factor).

Group A consisted of adults $(n=33)$ aged over 18. Group B consisted of children $(n=30)$ aged between 10 and 12 . The researcher found that negative syntactic transfer from L1 to L3 may occur more frequently among young learners than among old 
learners. Flynn et al. (2004) argued that the study results did not only reflect the effect of age on syntactic transfer in TLA (individual factor) but also proved that syntactical transfer could occur implicitly. This is because the participants in his study were children. One of the critical issues concerning this claim was that the participants of Group B (children) had only ILK of L1. For this group, participants' age varied between 10 and 12. Participants were school students exposed to L1 instructed teaching (explicit learning) and most likely developed certain ELK in their L1.

It is worth noting that Ellis et al. (2009) operationalized these two types of knowledge (ILK vs ELK). Furthermore, they designed the Untimed Grammaticality Judgment Test (UGJT) and the Metalinguistic Knowledge Test (MKT) to measure students' syntactical ELK of L2/L3. They also created The Oral Imitated Test (OEIT) and Timed Grammatical Judgment Test (TGJT) to measure students' syntactical ILK of $\mathrm{L}_{2} / \mathrm{L}_{3}$. These tests can be used in future research to monitor syntactical transfer in TLA in students' ILK and ELK of their newly learned language.

To examine syntactic transfer in TLA, one must consider the two factors leading to the development of learners' $\mathrm{L}_{3}$ linguistic knowledge. The first factor is the exposure to $\mathrm{L}_{3}$ syntactic linguistic input. The second factor is the positive syntactic transfer resulting from the common grammatical features between previously learned languages and the $\mathrm{L}_{3}$. Therefore, any claim of positive syntactic transfer influencing $\mathrm{L}_{3}$ proficiency must be carefully validated, as linguistic input also influences linguistic performance. In this review, most studies that examined positive syntactic transfer relied on post-study interviews, where participants declared that their usage of $\mathrm{L}_{3}$ syntactic rules was based on syntactic transfer from a previously learned language. The accuracy of a post-study interview is constrained by the limited ability of a participant to fully recall the causation determining the formation of their answers. Secondly, it has been well documented that processing the embedded structure of language input is largely implicit. This implies that learners will hardly be aware of any conscious transfer. One of the methods that could be useful in examining positive syntactic transfer in TLA is comparing the linguistic production of two groups pertaining to a specific syntactic rule: one group with an $\mathrm{L}_{3}$ that matches $\mathrm{L}_{1}$ and $\mathrm{L}_{2}$ in the examined syntactic rules and another group with L1 and L2 that are syntactically different from $\mathrm{L}_{3}$ pertaining to the examined syntactic rules. If participants of the first group perform better than the participants of the second group, this may indicate that positive transfer has occurred in the $\mathrm{L}_{3}$ syntactic production among participants of the first group. However, a participant's linguistic performance, in this case, is a result of both syntax transfer and $\mathrm{L}_{3}$ language input.

This paper discussed factors that influence syntactic transfer in TLA. Any future research conducted to evaluate any potential source of syntactic transfer in TLA must isolate all the factors presented in this paper. For instance, to assess participants' attentional control ability (individual factors) on syntactical transfer in TLA, all other factors should be held steady: linguistic (such as typology), individual (such as learners' attention control ability and age), psycholinguistic (such as psychotypology and the learners' awareness of cognates), and other factors (such as L2 type and amount of instruction). 


\section{Conclusion}

As a general statement and with regard to positive syntactical transfer in TLA, this review showed that typological similarity is the main generator of positive syntactic transfer from L1 and L2 into L3 (Rothman 2010; García Mayo, Slabakova 2015). It was found that when $\mathrm{L}_{1}, \mathrm{~L}_{2}$, and $\mathrm{L}_{3}$ are equally proximate, it is the $\mathrm{L}_{2}$ that has the primary influence on positive syntactic transfer in TLA (Bardel, Falk 2007; Falk, Bardel 2011). Some of the studies reviewed by this paper discussed the interaction across related languages $\left(\mathrm{L}_{1}, \mathrm{~L}_{2}, \mathrm{~L}_{3}\right)$ and their impact on syntactic transfer in TLA. In summary and concerning this interaction it was found that a low level of $\mathrm{L}_{3}$ ELK may promote positive syntactic transfer from $\mathrm{L}_{1}$ and $\mathrm{L}_{2}$ into $\mathrm{L}_{3}$ (Hermas 2015). This transfer occurs more frequently when participants have a high level of L1 and L2 ELK (Falk et al. 2015). Furthermore this review also found that a high level of $\mathrm{L}_{3}$ ELK may inhibit positive syntactic transfer from a previously learned language (L1, L2) (Hermas 2015).

This review provided readers with some additional suggestions pertaining to syntactic transfer in TLA. As each suggestion is supported by one study, the absolute validity of these suggestions can be subjected to further examination. These suggestions include two major points. Firstly, L3 adult learners are more aware of - and can exploit - typological similarities between $\mathrm{L}_{2}$ and $\mathrm{L}_{3}$, whereas children may count more on their $\mathrm{L}_{1}$ as a source of positive syntactic transfer into L3 (Flynn et al. 2004). Secondly, positive syntactic transfer from L1 and L2 into L 3 does not only depend on actual typological similarity between $\mathrm{L}_{2}$ to $\mathrm{L}_{3}$ but can also be influenced by a learner's perception of their similarity (Rothman 2010).

Claims of negative syntactic transfer are less contentious as these are more readily observed to be the outcome of syntactic transfer as opposed to linguistic instruction. However, when examining the impact of one specific factor (e.g. age) on syntactic transfer in TLA researchers must hold all other potential influential factors steady (e.g. L3 proficiency, L2 exposure). As a general statement this review showed that in TLA the typological dissimilarity across related languages is the main factor causing negative syntactic transfer from $\mathrm{L}_{1}$ and $\mathrm{L}_{2}$ into $\mathrm{L}_{3}$. However, it was also found when $\mathrm{L}_{1}, \mathrm{~L}_{2}$, and $\mathrm{L}_{3}$ are equally proximate, it is the $\mathrm{L}_{2}$ that has the primary influence on negative syntactic transfer in TLA (Bardel, Falk 2007). Some of the studies this paper reviewed examined the interaction across related languages $\left(\mathrm{L}_{1}, \mathrm{~L}_{2}, \mathrm{~L}_{3}\right)$ and their impact on syntactic transfer in TLA. In summary these studies found that a low or intermediate level of $\mathrm{L}_{3}$ proficiency may promote negative syntactic transfer from a previously learned language. They also found that this transfer mainly occurred when participants have a high level of proficiency in their L1 and L2 (Bardel, Falk 2007; Falk, Bardel 2011).

This review provided readers with some additional suggestions pertaining to negative syntactic transfer in TLA. As these suggestions are only supported by one research finding, further examinations on these subjects are required. These suggestions included three main points. Firstly, it was found that early L3 learning (age < 10 years) with a considerable amount of $\mathrm{L}_{3}$ instruction will only moderately inhibit 
negative grammatical transfer from $\mathrm{L}_{1}$ and $\mathrm{L}_{2}$ into $\mathrm{L}_{3}$, as confirmed by Pfenninger and Singleton (2016). Secondly, this review also found that a high "Attention Control Ability" in $\mathrm{L}_{3}$ learners may allow learners to inhibit negative syntactic transfer from L2 into L3 (Sanchez, Bardel 2016). Finally, it was found that in TLA an increase in the amount of L2 exposure through instruction of general and academic L2 may increase the rate of negative syntactic transfer from L2 into L3 (Stadt et al. 2018).

\section{References}

Bardel C., Falk Y. 2007. The role of the second language in third language acquisition: The case of Germanic syntax. - Second Language Research 23.4: 459-484.

Berns J., Jacobs H., Nouveau D. (eds.). 2018. Romance languages and linguistic theory 13: Selected papers from 'Going Romance' 29, Nijmegen. Nijmegen: John Benjamins Publishing Company.

Carreiras M., Clifton C. 1999. Another word on parsing relative clauses: Eyetracking evidence from Spanish and English. - Memory \& Cognition 27.5: 826-833.

Division 2001 = Common European framework of reference for languages: Learning, teaching, assessment. [Council of Europe]. Strasbourg: Cambridge University Press.

Dussias P.E. 2004. Parsing a first language like a second: The erosion of L1 parsing strategies in Spanish-English bilinguals. - International Journal of Bilingualism 8.3: 355-371.

Ellis R. 2015. Understanding second language acquisition. [2nd edition]. Oxford: Oxford University Press.

Ellis R., Loewen S., Elder C., Erlam R., Philp J., Reinders H. 2009. Implicit and explicit knowledge in second language learning, testing and teaching. Bristol, Buffalo, Toronto: Multilingual Matters.

Falk Y., Bardel C. 2011. Object pronouns in German L3 syntax: Evidence for the L2 status factor. - Second Language Research 27.1: 59-82.

Falk Y., Lindqvist C., Bardel C. 2015. The role of L1 explicit metalinguistic knowledge in L3 oral production at the initial state. - Bilingualism: Language and Cognition 18.2: 227-235.

Flynn S., Foley C., Vinnitskaya I. 2004. The cumulative-enhancement model for language acquisition: Comparing adults' and children's patterns of development in first, second and third language acquisition of relative clauses. - International Journal of Multilingualism 1.1: 3-16.

García Mayo M.D.P., Slabakova R. 2015. Object drop in L3 acquisition. - International Journal of Bilingualism 19.5: 483-498.

Gibson E., Pearlmutter N., Canseco-Gonzalez E., Hickok G. 1996. Recency preference in the human sentence processing mechanism. - Cognition 59.1: 23-59.

Gibson E., Pearlmutter N.J. 1998. Constraints on sentence comprehension. - Trends in Cognitive Sciences 2.7: 262-268.

Hermas A. 2015. The categorization of the relative complementizer phrase in third-language English: A feature re-assembly account. - International Journal of Bilingualism 19.5: 587-607.

Miyamoto E.T. 1998. Relative clause attachment in Brazilian Portuguese. [Unpublished manuscript. Massachusetts Institute of Technology. Cambridge (MA)].

Pfenninger S.E., Singleton D. 2016. Age of onset, socio-affect and cross-linguistic influence: a long-term classroom study. - Vigo International Journal of Applied Linguistics 13: 147-179. 
Rothman J. 2010. On the typological economy of syntactic transfer: Word order and relative clause high/low attachment preference in L3 Brazilian Portuguese. - IRAL-International Review of Applied Linguistics in Language Teaching 48.2-3: 245-273.

Rothman J., Cabrelli A.J. 2010. What variables condition syntactic transfer? A look the L3 initial state. - Second Language Research 26.2: 189-218.

Sanchez L., Bardel C. 2016. Cognitive factors, linguistic perceptions and transfer in third language learning. - Revue française de linguistique appliquée 21.2: 123-138.

Stadt R., Hulk A., Sleeman P. 2018. The role of L2 exposure in L3A. - Romance languages and linguistic theory 13: Selected papers from 'Going Romance'29, Nijmegen. Nijmegen: John Benjamins Publishing Company: 279-296. 
